\title{
Lignocellulosic Micro- and Nanomaterials as Copper Frames for the Evaluation of the Copper(I)-Catalyzed Azide-Alkyne Cycloaddition
}

\author{
Charles W. Owens, ${ }^{1}$ Gloria S. Oporto, ${ }^{1}$ Björn C. G. Söderberg, ${ }^{2}$ and Katherine E. Lambson ${ }^{2}$ \\ ${ }^{1}$ School of Natural Resources, West Virginia University, Morgantown, WV 26506, USA \\ ${ }^{2}$ C. Eugene Bennett Department of Chemistry, West Virginia University, Morgantown, WV 26506, USA \\ Correspondence should be addressed to Gloria S. Oporto; gloria.oporto@mail.wvu.edu
}

Received 22 February 2017; Accepted 15 June 2017; Published 18 July 2017

Academic Editor: Sohel Rana

Copyright (C) 2017 Charles W. Owens et al. This is an open access article distributed under the Creative Commons Attribution License, which permits unrestricted use, distribution, and reproduction in any medium, provided the original work is properly cited.

Copper was immobilized onto carboxymethyl cellulose, nanofibrillated cellulose, TEMPO-nanofibrillated cellulose, and lignin. The lignocellulosic frames were used with the aim of providing an effective support for catalyst copper and allowing its further reutilization. Each organic support was successful and effective in the coupling of copper with the exception of lignin. These complexes were used as heterogeneous catalysts to produce 1-benzyl-4-phenyl-1H-[1,2,3]-triazole from the copper(I)-catalyzed azide-alkyne cycloaddition (CuAAC) between benzyl azide and phenylacetylene. Each reaction was carried out in water and acetonitrile. Those performed in water were completed in 15 minutes while those done in acetonitrile were allowed to react overnight, reaching completion in less than 20 hours. The yields for $\mathrm{Cu}-\mathrm{CMC}$ resulted in over $90 \%$ for those reactions performed in acetonitrile. All catalysts were easy to recover except $\mathrm{Cu}$-lignin which could not be filtered or extracted from the reaction effluent.

\section{Introduction}

The "Huisgen click" reaction refers to an azide-alkyne 1,3dipolar cycloaddition. This reaction has many useful applications for drug discovery [1], polymer synthesis [2], and material science [3], among other biological applications [4, 5]. However, this reaction often requires high temperatures, has a low reaction rate, and typically produces a mixture of 1,5-substituted and 1,4-substituted triazoles [6].

Copper $(\mathrm{Cu})$ based catalyst for the "Huisgen click" reaction has received significant attention during the last decade due to its versatile reactivity and much lower cost compared with noble metals, such as $\mathrm{Pd}$ and $\mathrm{Rh}$. The rate of this copper(I)-catalyzed azide-alkyne cycloaddition (CuAAC) is increased by a factor of $10^{7}$ relative to the purely thermal process [6]. Most $\mathrm{CuAAC}$ procedures involve in situ reducing agents to reduce $\mathrm{Cu}(\mathrm{II})$ salts in the generation of $\mathrm{Cu}(\mathrm{I})$ catalysts [7]. This reaction is quite insensitive to its environment and is also unaffected by most functional groups, so it may be performed in an aqueous or organic solution. However, it is most commonly performed in a water/alcohol mixture $[6,8,9]$, though, without somehow immobilizing the copper on a homogeneous support, this CuAAC reaction is still very limited due to the low recoverability of copper from the product [10].

In general catalytic metal particles have been immobilized on solid supports that include the following: silica, alumina, zirconia, ceria, zeolites, glass fibers, and synthetic polymers [11-14]. The concept of sustainable chemistry is opening incredible opportunities for supporting materials coming from renewable natural polymers. Cellulose-based materials were studied as a support material for metal catalysts some years ago [15]. In recent years, the utilization of cellulose nanomaterials, such as cellulose nanofibers and cellulose nanocrystals, has demonstrated excellent performance to be used as scaffold for metal nanoparticles in catalysis [16-18]. Shen et al. in 2010 used $\mathrm{CuSO}_{4}$ reduced by sodium ascorbate to catalyze $O$-acetyl- $\alpha$-L-arabinopyranosyl azide and phenyl acetylene and found yields unsatisfactory at $54 \%$ [19]. The group then immobilized $\mathrm{Cu}$ onto microcrystalline 
cellulose as a catalyst, and the reaction (performed in water at $60^{\circ} \mathrm{C}$ ) produced a $93 \%$ yield, showing that a cellulosesupported copper catalyst is favorable. The group also reused the catalyst and, after five cycles, the yield was still favorable at $84 \%$, displaying excellent recoverability of the $\mathrm{Cu}(0)$ cellulose catalyst [20].

Reddy et al. used the same procedure and materials as $\mathrm{Yu}$ et al. to create the $\mathrm{Cu}(0)$-cellulose catalyst and had similar results in their catalyst formations, with $\mathrm{Cu} 2 \mathrm{P} \mathrm{X}$-ray photoelectron spectroscopy (XPS) spectra peaks around $932.7 \mathrm{eV}$. However, inductively coupled plasma atomic emission spectroscopy (ICP-AES) analysis in both studies show that Yu et al's $\mathrm{Cu}(0)$-cellulose had almost double the amount of copper compared to Reddy et al.'s at $0.730 \mathrm{mmol} / \mathrm{g}$ and $0.368 \mathrm{mmol} / \mathrm{g}$, respectively [20,21]. This could be due to the type of wood the cellulose was drawn from and, correspondingly, the amount of carboxylate groups on the cellulose fibers.

Koga et al. created a cellulose-supported $\mathrm{Cu}(\mathrm{I})$ catalyst using 2,2,6,6-tetramethylpiperidine-1-oxyl (TEMPO) nanofibrillated cellulose (TNFC). The azide-alkyne pair of benzyl azide and phenyl acetylene reacted in an aqueous solution of sodium ascorbate containing the $\mathrm{Cu}(\mathrm{I})$-TNFC catalyst; the copper content of the catalyst used in the reaction was $10 \mu \mathrm{mol}$. Through NMR analysis, the product was found to be entirely 1-benzyl-4-phenyl-1H-[1,2,3]-triazole, the desired product [17]. This indicates both the procedure and catalyst were very effective for this azide-alkyne cycloaddition.

Zhong et al. in 2013 used carboxymethyl cellulose (CMC) to immobilize copper that displayed excellent antimicrobial properties against Escherichia coli. Then, in 2015, Zhong et al. developed an efficient drying process for $\mathrm{Cu}-\mathrm{TNFC}$ and $\mathrm{Cu}-\mathrm{CMC}$ complexes-which was developed using the same procedure from Zhong et al. in 2013. The results of this procedure, through XPS analysis, showed that the oxidative state of copper in the final product was $\mathrm{Cu}^{+}$, which was the oxidative state of copper in the research previously discussed by Koga et al. in 2012. In this study, copper nanoparticles were supported on lignin and three different kinds of cellulose (CMC, NFC, and TNFC) for the cycloaddition of benzyl azide and phenyl acetylene. Similar processes to the production of $\mathrm{Cu}-\mathrm{CMC}$ [22], drying of the $\mathrm{Cu}-\mathrm{TNFC}$ and $\mathrm{Cu}-\mathrm{CMC}$ [23], and catalyst performance test of CuAAC [17] were used in this research.

\section{Materials and Methods}

2.1. Materials. Sodium carboxymethyl cellulose (Na-CMC) with average molecular weight of $90,000 \mathrm{~g} / \mathrm{mol}$ was purchased from Sigma-Aldrich, USA; nanofibrillated cellulose (NFC), $2.8 \mathrm{wt} \%$, from the University of Maine, USA; TEMPO-nanofibrillated cellulose (TNFC) gel, $0.96 \mathrm{wt} \%$, from Forest Products Laboratory, USA; lignin, alkali from Sigma-Aldrich, USA; copper sulfate pentahydrate $\left(\mathrm{CuSO}_{4} \cdot 5 \mathrm{H}_{2} \mathrm{O}\right)$ from Fisher Scientific, USA; sodium borohydride $\left(\mathrm{NaBH}_{4}\right), 0.5 \mathrm{M}$, from Acros, USA; ethanol (reagent alcohol, 95\%) from Sigma-Aldrich, USA; tertbutanol (99.5\%) from Acros, USA; benzyl azide (94\%) from Alfa Aesar, England; phenyl acetylene (98\%) from Alfa Aesar, England; sodium cyanoborohydride $\left(\mathrm{NaBH}_{3} \mathrm{CN}\right)$ from Sigma-Aldrich, USA.

\subsection{Preparation of Copper Catalysts}

2.2.1. Preparation of Copper-Carboxymethyl Cellulose. Sodium carboxymethyl cellulose (Na-CMC) $(1 \mathrm{~g})$ was suspended in deionized water $(49 \mathrm{~mL})$. After that, $\mathrm{CuSO}_{4}$ (aqueous, $15 \mathrm{~mL}, 0.1 \mathrm{M}$ ) was added dropwise to the solution under constant stirring. Once all the $\mathrm{CuSO}_{4}$ had been added, mixing immediately ceased, and the solution rested for $14 \mathrm{~h}$. Sodium borohydride (aqueous, $10 \mathrm{~mL}, 0.5 \mathrm{M}$ ) was added slowly under constant stirring over $30 \mathrm{~min}$ in order to reduce the oxidation state of copper [22].

2.2.2. Preparation of Copper-Nanofibrillated Cellulose. Nanofibrillated cellulose (NFC) gel (1 g, $2.8 \mathrm{wt} \%)$ was suspended in deionized water $\left(10 \mathrm{~mL}\right.$ ). After that, $\mathrm{CuSO}_{4}$ (aqueous, $4 \mathrm{~mL}, 0.1 \mathrm{M}$ ) was then added dropwise to the solution under constant stirring for $1 \mathrm{~h}$. Sodium borohydride (aqueous, $3 \mathrm{~mL}$, $0.5 \mathrm{M}$ ) was added as a reducer. Once added, the suspension underwent constant stirring for $30 \mathrm{~min}$.

\subsubsection{Preparation of Copper-TEMPO-Nanofibrillated Cellu-} lose. TEMPO-nanofibrillated cellulose gel $(5 \mathrm{~mL}, 0.96 \mathrm{wt} \%)$ was suspended in deionized water $(10 \mathrm{~mL})$. After that, $\mathrm{CuSO}_{4}$ (aqueous, $4 \mathrm{~mL}, 0.1 \mathrm{M}$ ) was then added dropwise to the solution under constant stirring for $1 \mathrm{~h}$. Next, to reduce the oxidation state of copper, sodium borohydride (aqueous, $3 \mathrm{~mL}, 0.5 \mathrm{M}$ ) was added and stirred for another $30 \mathrm{~min}$.

2.2.4. Preparation of Copper-Lignin. Lignin (1g) was suspended in deionized water $\left(10 \mathrm{~mL}\right.$ ). After that, $\mathrm{CuSO}_{4}$ (aqueous, $4 \mathrm{~mL}, 0.1 \mathrm{M}$ ) was then added dropwise to the solution under constant stirring for $1 \mathrm{~h}$. Lastly, sodium borohydride (aqueous, $3 \mathrm{~mL}, 0.5 \mathrm{M}$ ) was added slowly and then stirred with the suspension for $30 \mathrm{~min}$ to ensure all the copper had been reduced.

2.3. Drying and Purifying the Copper Catalysts. Each suspension was then centrifuged and the upper liquid layer was removed. The solids that remained were then redispersed in water $(50 \mathrm{~mL})$ and centrifuged again at $8000 \mathrm{rpm}$ for $5 \mathrm{~min}$. The upper clear solution was removed, and ethanol $(25 \mathrm{~mL})$ was mixed with the solid in the bottom of the vial. The vial was centrifuged again at $8000 \mathrm{rpm}$ for $5 \mathrm{~min}$, and the upper clear solution was subsequently removed. Ethanol was again mixed, and, after waiting for two hours upon mixing, the solution was centrifuged at $8000 \mathrm{rpm}$ for $5 \mathrm{~min}$. The upper liquid was then removed. This process was repeated using tert-butanol. The solid that remained from each suspension was then stored in a vacuum for 2 days to prevent oxidation and to allow the tert-butanol to dry. After the solids were dried under vacuum, they were placed in a freeze-dryer for 3 days [23]. Note that this process was only used to dry $\mathrm{Cu}-\mathrm{CMC}, \mathrm{Cu}-\mathrm{NFC}$, and $\mathrm{Cu}-\mathrm{TNFC}$. The $\mathrm{Cu}-$ lignin suspensions were not able to be separated from the solvent after centrifugation; therefore, the lignin suspension was placed directly in the freeze-dryer.

2.4. Catalyst Performance Test. Sodium cyanoborohydride (aqueous, $3.3 \mathrm{mM}, 30 \mathrm{~mL}$ ) was used to pretreat $\mathrm{Cu}-\mathrm{CMC}$ 


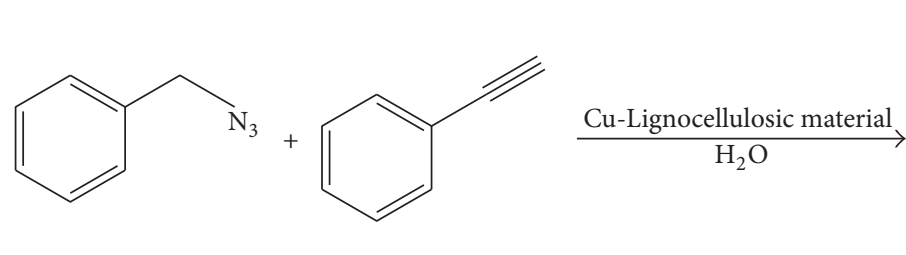

[A]

$[\mathrm{B}]$

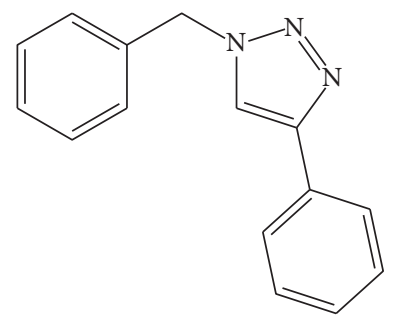

$[\mathrm{C}]$

FIGURE 1: Illustration of the CuAAC of benzyl azide and phenylacetylene to produce 1,4-BPT, where [A]: benzyl azide, [B]: phenylacetylene, and [C]: 1-benzyl-4-phenyl-1H-[1,2,3]-triazole (1,4-BPT).

(6 mg), Cu-NFC (11 mg), Cu-TNFC (14 mg), and Cu-lignin (200 mg) - all separately-at $70^{\circ} \mathrm{C}$ for $20 \mathrm{~min}$ prior to performing the CuAAC reaction. For the CuAAC reaction, benzyl azide $(125 \mu \mathrm{L}, 1.00 \mathrm{mmol})$ and phenylacetylene $(110 \mu \mathrm{L}$, $1.00 \mathrm{mmol}$ ) were added to each solution under constant stirring at $70^{\circ} \mathrm{C}$ [17]. The $\mathrm{CuAAC}$ reaction is represented in Figure 1. The progress of the reaction was monitored by thin layer chromatography (TLC, hexane/EtOAc, $19: 1$ ). After the complete disappearance of benzyl azide, the catalyst was recovered from the mixture by filtration and washed with water $(2 \times 10 \mathrm{~mL})$ and acetone $(2 \times 10 \mathrm{~mL})$ and then allowed to dry in a vacuum. The filtrate was extracted with ethyl acetate $(3 \times 30 \mathrm{~mL})$. The combined organic phases were dried $\left(\mathrm{MgSO}_{4}\right)$ and filtered and filtrate was concentrated in vacuum [20]. The crude product was purified by filtration through a short plug of silica gel eluting with EtOAc to yield 1-benzyl4-phenyl-1H-[1,2,3]-triazole (1,4-BPT).

This process was then repeated using $\mathrm{Cu}-\mathrm{CMC}$ and scaled up by a factor of 5 in order to reduce human error. In addition to scale-up, the recovered catalyst was reused twice for the same reaction to analyze catalytic decay.

This scaled-up process was also repeated using $\mathrm{Cu}-\mathrm{CMC}$ in $30 \mathrm{~mL}$ of acetonitrile, a common solvent medium for $\mathrm{CuAAC}$, instead of $30 \mathrm{~mL}$ of water. This was done to compare with other literature, as water is not typically used as the solvent in this CuAAC since copper easily dissolves in water. However, water is a very desirable reaction medium due to its abundance and environmental sustainability.

2.5. Characterization. The copper loading on each catalyst support was determined using Varian Vista-PRO CCD simultaneous inductively coupled plasma-optical emission spectroscopy (ICP-OES) (Palo Alto, USA). In order to prepare these samples for ICP-OES, $30 \mathrm{mg}$ of each catalyst was dissolved in $1 \mathrm{~mL}$ of nitric acid $(71 \mathrm{wt} \%)$. When the solid complexes were completely dissolved, the solution was diluted with $99 \mathrm{~mL}$ of deionized water and $15 \mathrm{~mL}$ of this solution was then used for ICP-OES analysis.

The oxidation state of copper on each catalyst was determined using Physical Electronics VersaProbe 5000 X-ray Photoelectron Spectroscopy (XPS) system with a monochromatic Aluminum K $\alpha$ X-ray source (Chanhassen, MI, USA). The base pressure in the high vacuum analysis chamber was around $2 \times 10^{-6} \mathrm{~Pa}$. An Aluminum X-ray source of $1486.6 \mathrm{eV}$ was used for photoelectron excitation with X-ray power of $25 \mathrm{~W}$. Pass energies of $117.4 \mathrm{eV}$ for survey scan and $23.5 \mathrm{eV}$ for detailed scan were used for the data acquisition with energy steps of $0.5 \mathrm{eV}$ for survey scan and $0.05 \mathrm{eV}$ for detailed scan, respectively. PHI MultiPak software was used for element identification and peak fitting. The $\mathrm{Cls}$ peak at a binding energy of $284.8 \mathrm{eV}$ was used as the internal reference. A Shirley-type background was subtracted from the spectra and Gauss-Lorentz curves were used to fit the spectra.

The solid product from the CuAAC reaction was dissolved in deuterochloroform and nuclear magnetic resonance $\left({ }^{1} \mathrm{H}\right.$ NMR) measurements were taken using a $400 \mathrm{MHz}$ Agilent Technologies NMR, Model Number 400/54/ASP. Data analysis was performed using Agilent Technologies Software VNMRJ, Version 2.4, Revision A.

2.6. Yield Determination. The yield of each reaction was determined in the following equation:

$$
\frac{\text { Theoretical Yield }- \text { Actual Yield }}{\text { Theoretical Yield }} \times 100 \text {. }
$$

\section{Results and Discussion}

3.1. Production of Copper Catalysts. ICP-OES analysis calculated the amount of copper on each catalyst. Three samples of each complex were used in order to gain an accurate knowledge of the loading of copper onto each organic support. Figure 2 displays the results from ICP-OES. The number above each bar indicates the average mmol of $\mathrm{Cu}$ per gram of catalyst. The error bars indicate the standard deviation for all the trials for each sample. These error bars represent the amount of variation of copper throughout the catalyst. The results are excellent when compared to literature.

$\mathrm{Yu}$ et al. used microcrystalline cellulose as the platform to attach copper, and the copper loading onto the microcrystalline cellulose only resulted in $0.730 \mathrm{mmol} \mathrm{Cu} / \mathrm{g}$ catalyst [20]. All of our compounds except Cu-lignin (due to the procedure in which it was created) have higher copper loadings than this, and CMC has over 2.5 times the copper loading of the microcrystalline cellulose. From these results, it can be concluded that $\mathrm{CMC}$ is the best organic compound on which to immobilize copper nanoparticles. This is likely due to the presence of high number of $\mathrm{Na}$-carboxyl groups 


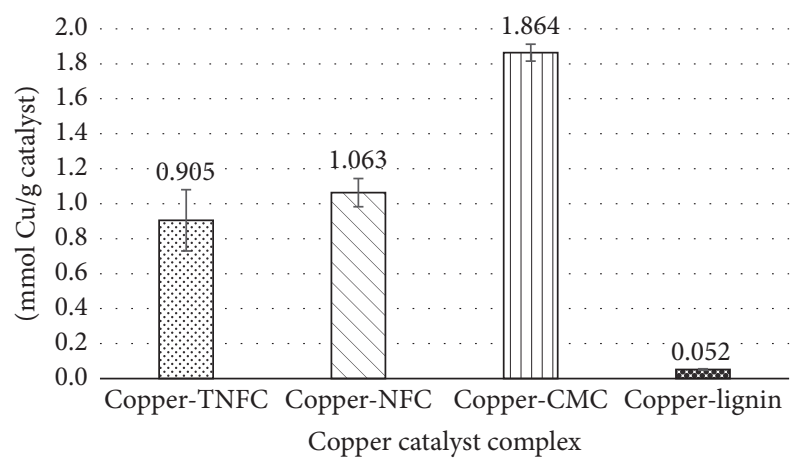

FIGURE 2: Amount of copper per gram of catalyst on each hybrid material.

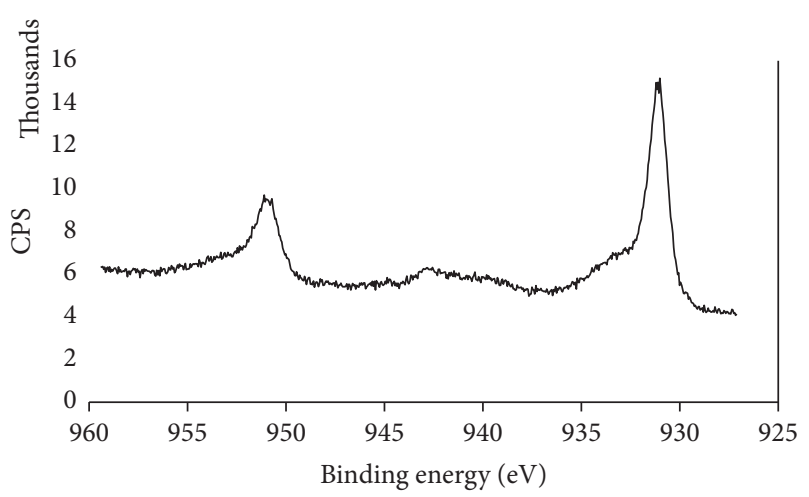

FIgURE 3: XPS spectra of $\mathrm{Cu}-\mathrm{CMC}$.

that can facilitate the copper reduction and therefore its further availability.

As determined from XPS the state of oxidation was $\mathrm{Cu}(\mathrm{I})$ for all complexes. There were strong peaks around 931-932 and 950-951 with a weak satellite peak between the two around 943. This weak satellite peak was the determining factor for the oxidation state because it is unique to the $\mathrm{Cu}(\mathrm{I})$ oxidation state only. Figure 3 displays the XPS data graphically for $\mathrm{Cu}-\mathrm{CMC}$. All data for the remaining complexes are very similar and therefor will not be displayed along with the $\mathrm{Cu}-\mathrm{CMC}$.

\subsection{Catalyst Performance Test}

3.2.1. Using Water as Media for the Reaction. The reaction time was outstanding for each catalyst, with each reaction reaching completion in 15 minutes. Compared to Koga et al., who used softwood-derived TNFC as a catalyst support for the same reaction, our copper-cellulose complexes catalyzed the reaction $5 \mathrm{~min}$ faster [17]. However, the yields for 1,4-BPT were not satisfactory. Table 1 presents information regarding the yields pertaining to each catalyst.

One thing to note as well is that the $\mathrm{Cu}$-lignin was irrecoverable from the reaction. It appears to have dissolved in the aqueous layer.

Table 2 shows the results of the scaled-up reaction using $\mathrm{Cu}-\mathrm{CMC}$ and the same reaction reusing the catalyst.

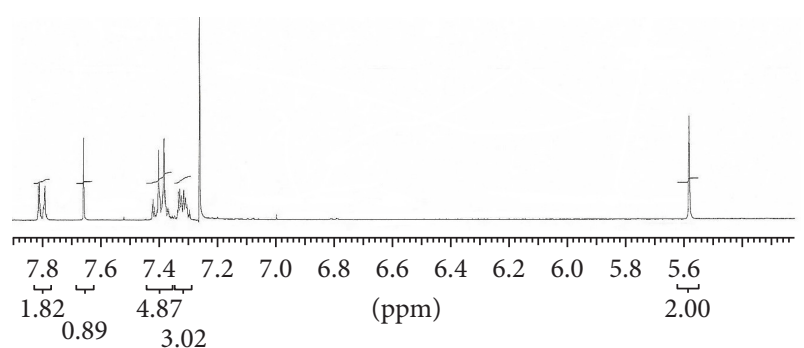

FIGURE 4: NMR results for material produced from procedure used in this research.

TABLE 1: Yield information of each CuAAC using different catalysts.

\begin{tabular}{lcc}
\hline Catalyst proposed & 1,4-BPT yield $(\mathrm{mg})$ & Yield percentage \\
\hline Cu-CMC & 131 & $56 \%$ \\
Cu-NFC & 85 & $36 \%$ \\
Cu-TNFC & 136 & $58 \%$ \\
Cu-lignin & 90 & $39 \%$ \\
\hline
\end{tabular}

TABLE 2: Results of CuAAC using and reusing $\mathrm{Cu}-\mathrm{CMC}$.

\begin{tabular}{lcc}
\hline Catalyst use & Reaction time & Yield percentage \\
\hline 1 & $10 \mathrm{~min}$ & $45 \%$ \\
2 & $20 \mathrm{~min}$ & $43 \%$ \\
3 & $150 \mathrm{~min}$ & $38 \%$ \\
\hline
\end{tabular}

These results show that the first reuse of the catalyst is still very effective as the reaction time was still very fast, only increasing by 10 minutes. However, after reusing the catalyst once again, the reaction time increased greatly to $150 \mathrm{~min}$ suggesting the catalyst is not be reused more than once.

The low yields could be due to the extraction and purification process of the product, as there is much room for human error in this procedure. When using an internal standard of 1,4-dimethoxy benzene, NMR analysis showed yields of over $80 \% 1,4$-BPT. This indicates that improvements can be made to purification in order to isolate the entire desired product that is formed.

The results of the ${ }^{1} \mathrm{H}$ NMR analysis from $\mathrm{Cu}-\mathrm{CMC}$ as catalyst were as follows: $\delta_{\mathrm{H}} \mathrm{ppm}: 7.80(\mathrm{~d}, 2 \mathrm{H}), 7.66(\mathrm{~s}, 1 \mathrm{H})$, 7.36-7.42 (m, 5H), 7.34-7.29 (m, 3H), and $5.58(\mathrm{~s}, 2 \mathrm{H})$. The data are shown graphically in Figure 4; the numbers below the $x$-axis are the areas under each spike (or group of spikes) and represent the number of hydrogen atoms on each carbon. The most indicative datum on Figure 4 is the spike around $5.6 \mathrm{ppm}$. This is the carbon with two single bonds connecting the phenyl group to the azide group. Since it is known that there are two hydrogen atoms at this point and therefore the area under the spike will be exactly 2 , this data was implemented into the analysis and all other areas under each spike were determined using this data as the standard. The large spike around $7.25 \mathrm{ppm}$ is from the solvent, deuterochloroform, used to dissolve the product for analysis. Since every single area under each spike or group of spikes concurred with literature $[17,24]$, the results indicate the product was entirely 1,4-BPT using each copper complex as the catalyst. 
TABLE 3: Yield information using acetonitrile as reaction medium.

\begin{tabular}{lcc}
\hline Catalyst proposed & 1,4-BPT yield $(\mathrm{mg})$ & Yield percentage \\
\hline $\mathrm{Cu}-\mathrm{CMC}$ & 1070 & $91 \%$ \\
$\mathrm{Cu}-\mathrm{TNFC}$ & 872 & $74 \%$
\end{tabular}

The reaction completely favors the formation of 1,4substituted triazoles as well, differing from the thermal reaction which often results in a mixture of 1,4-substitued and 1,5 -substituted triazoles [6].

3.2.2. Acetonitrile as Media for the Reaction. Considering that the highest yields in water as media were for $\mathrm{Cu}$-CMC and $\mathrm{Cu}$-TNFC, they were tested in acetonitrile to evaluate differences. The results in this regard are presented in Table 3. When using acetonitrile as the solvent for the reaction and CMC-Cu as catalyst, $5 \mathrm{mmol}$ of reactant yielded $1.07 \mathrm{~g}(91 \%$ yield) of 1,4-BPT. These results are very comparable to other researches $[24,25]$ concluding that $\mathrm{CMC}$ is an effective support for copper to be used as a catalyst. In terms of $\mathrm{Cu}$ TNFC, yields were less satisfactory at $74 \%$, though much improved from the reaction in a water medium.

\section{Conclusions}

$\mathrm{Cu}$-cellulose was easily prepared using CMC, NFC, TNFC, and lignin. These complexes were then used as catalysts in the CuAAC between benzyl azide and phenylacetylene to produce 1,4-BPT. Water and acetonitrile as media for the reaction were used. In water media, the catalysts, with the exception of lignin, were easy to recover, displaying the low hazardous impact the reaction has on the environment. The reaction was complete in 15 minutes for each copper complex, showing the excellent catalytic ability of each heterogeneous catalyst. $\mathrm{Cu}-\mathrm{CMC}$ and $\mathrm{Cu}$-TNFC displayed the highest yields and were subsequently used as catalysts when acetonitrile was utilized as media for the reaction. The reaction in this case needed longer time to be completed and the yield resulted higher for $\mathrm{Cu}-\mathrm{CMC}$. Based on the process used to fabricate the hybrid $\mathrm{Cu}$-cellulose materials, CMC appears to be the best support for copper of the four organic compounds used as it held the most copper due to its higher number of Na-carboxyl groups and yielded one of the highest amounts of 1,4-BPT. Further investigation will be directed on the improvement of copper attachment on the lignocellulosic raw material for the specific application in the catalysis field.

\section{Abbreviations}

1,4-BPT: 1-Benzyl-4-phenyl-1H-1,2,3-triazole

CMC: Carboxymethyl cellulose

CuAAC: Copper azide-alkyne cycloaddition

TEMPO: 2,2,6,6-Tetramethylpiperidine-1-oxyl radical

NFC: Nanofibrillated cellulose

TNFC: TEMPO-nanofibrillated cellulose

ICP-AES: Inductively coupled plasma atomic emission spectroscopy
ICP-OES: Inductively coupled plasma-optical emission spectrometry

NMR: Nuclear magnetic resonance

TLC: $\quad$ Thin layer chromatography

XPS: X-ray photoelectron spectroscopy.

\section{Conflicts of Interest}

The authors declare that they have no conflicts of interest.

\section{Acknowledgments}

This work was supported by the USDA National Institute of Food and Agriculture, McIntire-Stennis, 1007636-WVA00119, "Advanced Applications for Nanomaterials from Lignocellulosic Sources."

\section{References}

[1] H. C. Kolb and K. B. Sharpless, "The growing impact of click chemistry on drug discovery," Drug Discovery Today, vol. 8, no. 24, pp. 1128-1137, 2003.

[2] J. F. Lutz, "1,3-dipolar cycloadditions of azides and alkynes: a universal ligation tool in polymer and materials science," Angewandte Chemie International Edition, vol. 46, no. 7, pp. 1018-1025, 2007.

[3] G. Delaittre, N. K. Guimard, and C. Barner-Kowollik, "Cycloadditions in modern polymer chemistry," Accounts of Chemical Research, vol. 48, no. 5, pp. 1296-1307, 2015.

[4] A. Martinez, C. O. Mellet, and J. M. G. Fernández, "Cyclodextrin-based multivalent glycodisplays: covalent and supramolecular conjugates to assess carbohydrate-protein interactions," Chemical Society Reviews, vol. 42, no. 11, pp. 4746-4773, 2013.

[5] V. Aragão-Leoneti, V. L. Campo, A. S. Gomes, R. A. Field, and I. Carvalho, "Application of copper(I)-catalysed azide/alkyne cycloaddition (CuAAC) 'click chemistry' in carbohydrate drug and neoglycopolymer synthesis," Tetrahedron, vol. 66, no. 49, pp. 9475-9492, 2010.

[6] J. E. Hein and V. V. Fokin, "Copper-catalyzed azide-alkyne cycloaddition (CuAAC) and beyond: new reactivity of copper(I) acetylides," Chemical Society Reviews, vol. 39, no. 4, pp. 1302-1315, 2010.

[7] V. Hong, S. I. Presolski, C. Ma, and M. G. Finn, "Analysis and optimization of copper-catalyzed azide-alkyne cycloaddition for bioconjugation," Angewandte Chemie International Edition, vol. 48, no. 52, pp. 9879-9883, 2009.

[8] M. Meldal and C. W. Tomøe, "Cu-catalyzed azide-alkyne cycloaddition," Chemical Reviews, vol. 108, no. 8, pp. 2952-3015, 2008.

[9] V. D. Bock, H. Hiemstra, and J. H. Van Maarseveen, "Cu ${ }^{I}$ catalyzed alkyne-azide 'click' cycloadditions from a mechanistic and synthetic perspective," European Journal of Organic Chemistry, no. 1, pp. 51-68, 2006.

[10] B. Dervaux and F. E. Du Prez, "Heterogeneous azide-alkyne click chemistry: towards metal-free end products," Chemical Science, vol. 3, no. 4, pp. 959-966, 2012.

[11] J. D. Aiken III and R. G. Finke, "Polyoxoanion- and tetrabutylammonium-stabilized $\mathrm{Rh}(0)_{n}$ nanoclusters: Unprecedented nanocluster catalytic lifetime in solution," Journal of the American Chemical Society, vol. 121, no. 38, pp. 8803-8810, 1999. 
[12] M. P. Campello, M. Balbina, I. Santos, P. Lubal, R. Ševčík, and R. Ševčíková, "Lanthanide(III) complexes of 2-[4,7,10-tris (phosphonomethyl)-1,4,7,10- tetraazacyclododecan-1-yl]acetic acid $\left(\mathrm{H}_{7} \mathrm{DOA} 3 \mathrm{P}\right)$ : multinuclear-NMR and kinetic studies," Helvetica Chimica Acta, vol. 92, no. 11, pp. 2398-2413, 2009.

[13] M. L. Kantam, G. T. Venkanna, C. Sridhar, B. Sreedhar, and B. M. Choudary, "An efficient base-free $N$-arylation of imidazoles and amines with arylboronic acids using copper-exchanged fluorapatite," Journal of Organic Chemistry, vol. 71, no. 25, pp. 9522-9524, 2006.

[14] T. Veerakumar, S. Esakkirajan, and I. Vennila, "Salt and pepper noise removal in video using adaptive decision based median filter," in Proceedings of the International Conference on Multimedia, Signal Processing and Communication Technologies (IMPACT '11), pp. 87-90, Aligarh, India, December 2011.

[15] B. Azambre, O. Heintz, A. Krzton, J. Zawadzki, and J. V. Weber, "Cellulose as a precursor of catalyst support: new aspects of thermolysis and oxidation-IR, XPS and TGA studies," Journal of Analytical and Applied Pyrolysis, vol. 55, no. 1, pp. 105-117, 2000.

[16] S. Barua, G. Das, L. Aidew, A. K. Buragohain, and N. Karak, "Copper-copper oxide coated nanofibrillar cellulose: a promising biomaterial," RSC Advances, vol. 3, no. 35, pp. 14997-15004, 2013.

[17] H. Koga, A. Azetsu, E. Tokunaga, T. Saito, A. Isogai, and T. Kitaoka, "Topological loading of $\mathrm{Cu}(\mathrm{I})$ catalysts onto crystalline cellulose nanofibrils for the Huisgen click reaction," Journal of Materials Chemistry, vol. 22, no. 12, pp. 5538-5542, 2012.

[18] Z. Zhou, C. Lu, X. Wu, and X. Zhang, "Cellulose nanocrystals as a novel support for $\mathrm{CuO}$ nanoparticles catalysts: facile synthesis and their application to 4-nitrophenol reduction," RSC Advances, vol. 3, no. 48, pp. 26066-26073, 2013.

[19] C. Shen, H. Zheng, P. Zhang, and X. Chen, "Synthesis of some novel glucosyl triazoles from 2,3,4,6-Tetra-O-pivaloyl-Dglucopyranosyl azide," Journal of Carbohydrate Chemistry, vol. 29, no. 4, pp. 155-163, 2010.

[20] W. Yu, L. Jiang, C. Shen, W. Xu, and P. Zhang, "A highly efficient synthesis of $N$-glycosyl-1,2,3-triazoles using a recyclable cellulose-copper(0) catalyst in water," Catalysis Communications, vol. 79, pp. 11-16, 2016.

[21] K. R. Reddy, N. S. Kumar, B. Sreedhar, and M. L. Kantam, " $N$-Arylation of nitrogen heterocycles with aryl halides and arylboronic acids catalyzed by cellulose supported copper(0)," Journal of Molecular Catalysis A: Chemical, vol. 252, no. 1-2, pp. 136-141, 2006.

[22] T. Zhong, G. S. Oporto, J. Jaczynksi, A. T. Tesfai, and J. Armstrong, "Antimicrobial properties of the hybrid copper nanoparticles-carboxymethyl cellulose," Wood and Fiber Science, vol. 45, no. 2, pp. 215-222, 2013.

[23] T. Zhong, G. S. Oporto, Y. Peng, X. Xie, and D. J. Gardner, "Drying cellulose-based materials containing copper nanoparticles," Cellulose, vol. 22, no. 4, pp. 2665-2681, 2015.

[24] B. R. Buckley, S. E. Dann, D. P. Harris, H. Heaney, and E. C. Stubbs, "Alkynylcopper(I) polymers and their use in a mechanistic study of alkyne-azide click reactions," Chemical Communications, vol. 46, no. 13, pp. 2274-2276, 2010.

[25] K. Kamata, Y. Nakagawa, K. Yamaguchi, and N. Mizuno, "1,3-Dipolar cycloaddition of organic azides to alkynes by a dicopper-substituted silicotungstate," Journal of the American Chemical Society, vol. 130, no. 46, pp. 15304-15310, 2008. 

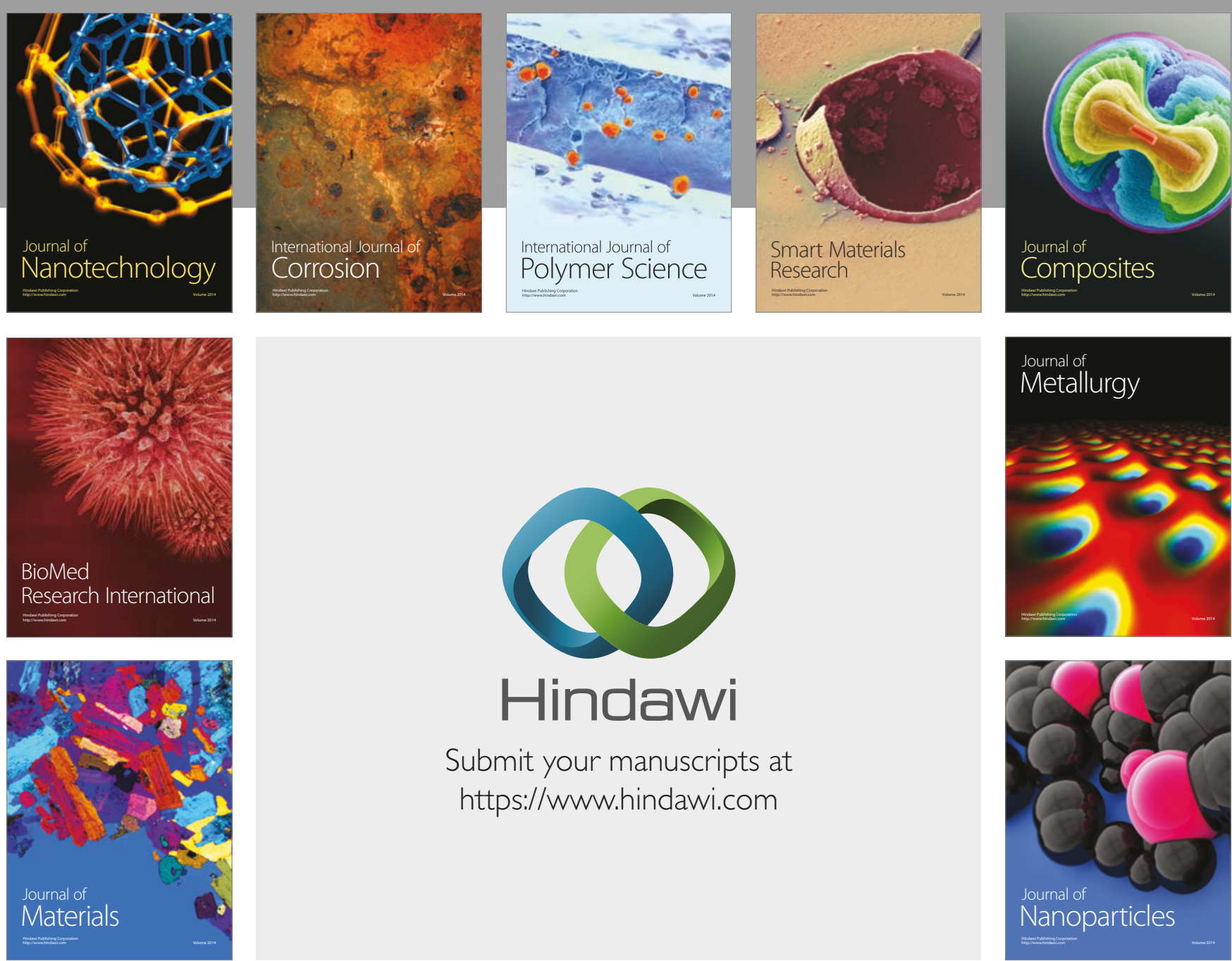

\section{Hindawi}

Submit your manuscripts at

https://www.hindawi.com
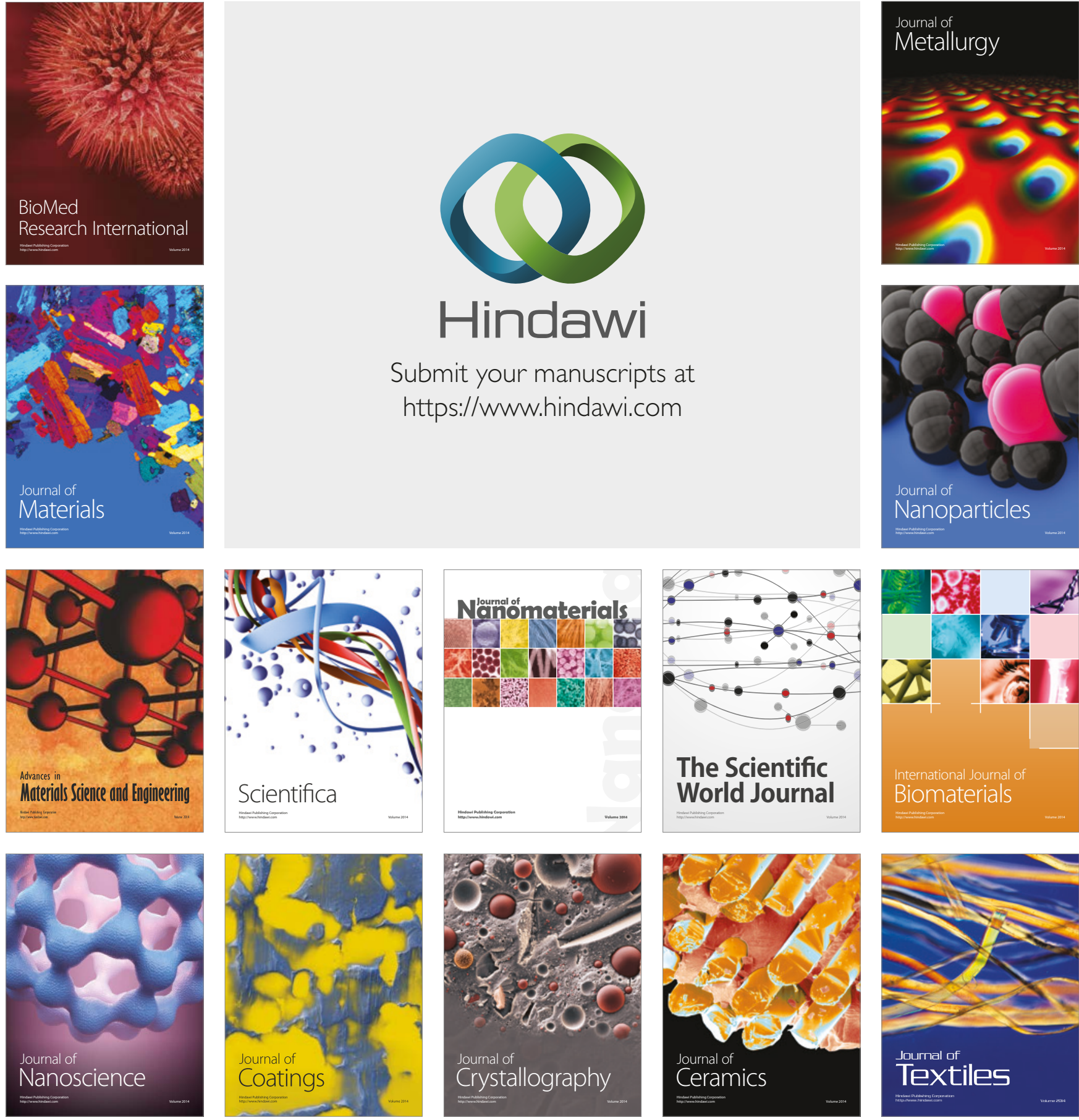

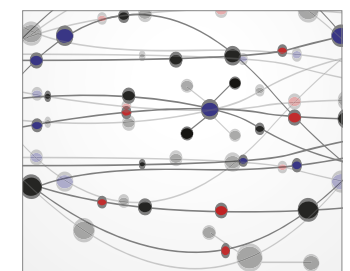

The Scientific World Journal
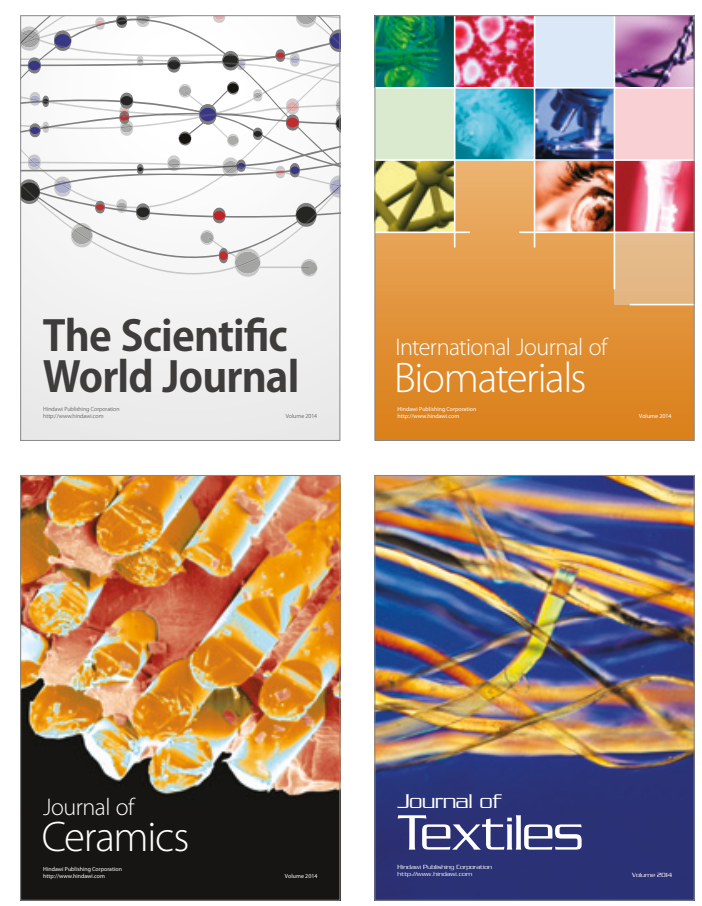